\title{
VALIDATION OF A DISCRETE CRACK MODEL FOR LIGHTWEIGHT AGGREGATE CONCRETE BEAMS
}

\author{
D. Dias-da-Costa ${ }^{1,2}$, R. Graça-e-Costa ${ }^{3}$, and R.N.F. Carmo ${ }^{4}$ \\ ${ }^{1}$ School of Civil Engineering, The University of Sydney, Sydney, NSW 2006, Australia \\ ${ }^{2}$ ISISE, University of Coimbra, Rua Luís Reis Santos, 3030-788 Coimbra, Portugal \\ e-mail: daniel.diasdacosta@sydney.edu.au \\ ${ }^{3}$ CEPAC, Universidade do Algarve \\ Campus de Gambelas, 8005-139 Faro, Portugal \\ e-mail: rcosta@ualg.pt \\ ${ }^{4}$ ICIST, Polytechnic Institute of Coimbra \\ Rua Pedro Nunes, 3030-199 Coimbra, Portugal \\ e-mail: carmo@isec.pt
}

Keywords: Discrete cracks, Lightweight concrete, Crack opening, Flexural behaviour.

\begin{abstract}
The development of crack models capable of simulating the discrete nature of fracture is of interest to many different areas of research. For example, the structural analysis innovative designs now made possible by new ultra-high performance concrete mixtures would certainly benefit from such improved predictive capabilities. Currently, there are numerous numerical approaches available in the literature, for instance based on nodal or element enrichment techniques, or even on remeshing strategies. Typically, the validation of such approaches was achieved using benchmark tests that contained few cracks and where the overall displacements were compared until failure. Having this into account, this paper describes a detailed validation of a discrete crack model based on embedded discontinuities for predicting the behaviour of lightweight aggregate concrete. The model itself includes the rigid body movements associated with the opening of cracks and relies on a robust noniterative algorithm to overcome convergence difficulties typically found with numerous cracks and material non-linearities. Validation was achieved using experimental data from tests performed on lightweight concrete beams (LWAC) under flexural load, where displacements, curvatures and cracks width were properly monitored. This data include, not only overall displacements, but also the complex crack patterns produced during the tests. The model was shown to predict well the overall crack patterns and openings, and was used to perform extrapolations on crack widths for different reinforcement ratios.
\end{abstract}




\section{INTRODUCTION}

There are many situations where the accurate prediction of the fractured behaviour of a structure requires models with the capability of simulating discrete cracks. This is true whenever the interaction between cracks and other structural features - e.g. reinforcement or strengthening materials - is critical to identify premature failures and to characterise the structural behaviour under serviceability conditions. Currently, there are many different approaches available in the literature, which can simulate material separation. Most approaches are based on nodal [1-4] or element enrichment techniques [5-11], or even on remeshing strategies [12-14]. These approaches were typically validated using benchmark tests with few cracks and by comparing overall displacements. Starting from this observation, this paper describes a validation study concerning a discrete crack model for embedding discontinuities and that can be efficiently used for predicting the behaviour of lightweight aggregate concrete (LWAC). The reason underlying the choice of LWAC is related to the fact of this cementitious material being relatively new in the field of civil engineering and currently facing many new applications. As example, it can be mentioned the strengthening of existing structures and the new structures being built with reduced overall gravity load, which impacts directly the design of the structural members and, indirectly, because of the decreased magnitude of seismic actions [15-17].

Until recently, most research in the field of LWAC was focused on the material behaviour from an experimental perspective [18-22], lacking numerical models that can be efficiently used for predicting the structural behaviour. Simultaneously, existing standards still need proper validation, in which case a robust numerical model will be needed to support further studies. Developed within this context, the model presented in this paper assumes the opening of the cracks to occur as if it were a rigid body movement and relies on a robust non-iterative algorithm to overcome potential convergence difficulties found in the presence of numerous cracks and material non-linearities. In the following sections, the model is described in detail and validated using experimental data from tests performed on light-weight concrete beams under flexural loads, focusing the overall displacements and the complex crack patterns produced during the tests.

\section{DISCRETE CRACK APPROACH}

\subsection{Variational framework}

The variational principle for a body $\Omega$ containing a surface of discontinuity, $\Gamma_{d}$, splitting it into two subdomains, $\Omega^{-}$and $\Omega^{+}$, and subjected to quasi-static body forces $\mathbf{b}$ and stresses t distributed over the external boundary, $\Gamma_{t}$, is given by [23]:

$$
\int_{\Omega \backslash \Gamma_{d}}\left(\nabla^{\mathrm{s}} \delta \mathbf{u}\right): \sigma(\varepsilon) d \Omega+\int_{\Gamma_{d}} \delta \llbracket \mathbf{u} \rrbracket \cdot \mathbf{t}^{+} d \Gamma=\int_{\Omega \backslash \Gamma_{d}} \delta \mathbf{u} \cdot \mathbf{b} d \Omega+\int_{\Gamma_{t}} \delta \mathbf{u} \cdot \mathbf{t} d \Gamma,
$$

where $\sigma$ is the stress tensor and $\mathbf{t}^{+}$is the stress at the crack, $\llbracket \mathbf{u} \|$ is the opening of the crack, and $\mathbf{u}$ is the total displacement field.

The total displacement can be considered to be the sum of two contributions, the regular displacement field, $\hat{\mathbf{u}}$, and the enhanced displacement field, $\tilde{\mathbf{u}}$, according to which:

$$
\delta \mathbf{u}=\delta \hat{\mathbf{u}}+H_{\Gamma_{d}} \delta \tilde{\mathbf{u}},
$$

where $H_{\Gamma_{d}}$ is the standard Heaviside function, with value ' 1 ' on $\Omega^{+}$(and ' 0 ' otherwise). 
For small displacements:

$$
\nabla^{\mathrm{s}} \delta \mathbf{u}=\nabla^{\mathrm{s}} \delta \hat{\mathbf{u}}+H_{\Gamma_{d}}\left(\nabla^{\mathrm{s}} \delta \tilde{\mathbf{u}}\right)+\delta_{\Gamma_{d}}\left(\llbracket \mathbf{u} \rrbracket \otimes \mathbf{n}^{+}\right)^{s},
$$

where $H_{\Gamma_{d}}$ is the Dirac's delta function along the surface of discontinuity and $\mathbf{n}^{+}$the vector orthogonal to the discontinuity and pointing inwards $\Omega^{+}$.

If the opening of the discontinuity is transmitted as if it were a rigid body motion, then $\nabla^{\mathrm{s}} \delta \tilde{\mathbf{u}}=\mathbf{0}$. By replacing Eqs. (2) and (3) in Eq. (1), and by taking $\delta \tilde{\mathbf{u}}=\mathbf{0}$ and then $\delta \hat{\mathbf{u}}=\mathbf{0}$, the following governing equations is derived:

$$
\begin{aligned}
& \int_{\Omega \backslash \Gamma_{d}}\left(\nabla^{\mathbf{s}} \delta \hat{\mathbf{u}}\right): \sigma(\hat{\varepsilon}) d \Omega=\int_{\Omega \backslash \Gamma_{d}} \delta \hat{\mathbf{u}} \cdot \mathbf{b} d \Omega+\int_{\Gamma_{t}} \delta \hat{\mathbf{u}} \cdot \mathbf{t} d \Gamma \\
& \int_{\Gamma_{d}} \delta \| \mathbf{u} \rrbracket \cdot \mathbf{t}^{+} d \Gamma=\int_{\Omega^{+}} \delta \tilde{\mathbf{u}} \cdot \mathbf{b} d \Omega+\int_{\Gamma_{t^{+}}} \delta \tilde{\mathbf{u}} \cdot \mathbf{t} d \Gamma
\end{aligned}
$$

\subsection{Discretisation}

Assuming that the body is discretised into a set of finite elements, the displacement field within each element containing a crack is interpolated by:

$$
\begin{aligned}
& \mathbf{u}^{e}=\mathbf{N}^{e}\left(\hat{\mathbf{a}}+H_{\Gamma_{d}}^{e} \mathbf{M}_{w}^{e k} \mathbf{w}^{e}\right) \text { in } \Omega^{e} \backslash \Gamma_{d}^{e}, \\
& \llbracket \mathbf{u} \rrbracket^{e}=\mathbf{M}_{w}^{e} \mathbf{w}^{e}=\mathbf{N}_{w}^{e} \mathbf{w}^{e} \text { at } \Gamma_{d}^{e}
\end{aligned}
$$

where $\mathbf{N}^{e}$ is a matrix with the shape functions of the element, $\hat{\mathbf{a}}$ are the nodal degrees of freedom associated with $\hat{\mathbf{u}}^{e}, \mathbf{w}^{e}$ are the degrees of freedom for the opening of the crack at both extremities, $\mathbf{N}_{w}^{e}$ contains linear interpolation functions and matrix $\mathbf{M}_{w}^{e}$ is defined as:

$$
\mathbf{M}_{w}^{e}=\left[\begin{array}{cccc}
1-\frac{\left(x_{2}-x_{2}^{i}\right) \sin \alpha^{e}}{l_{d}^{e}} & \frac{\left(x_{2}-x_{2}^{i}\right) \cos \alpha^{e}}{l_{d}^{e}} & \frac{\left(x_{2}-x_{2}^{i}\right) \sin \alpha^{e}}{l_{d}^{e}} & -\frac{\left(x_{2}-x_{2}^{i}\right) \cos \alpha^{e}}{l_{d}^{e}} \\
\frac{\left(x_{1}-x_{1}^{i}\right) \sin \alpha^{e}}{l_{d}^{e}} & 1-\frac{\left(x_{1}-x_{1}^{i}\right) \cos \alpha^{e}}{l_{d}^{e}} & -\frac{\left(x_{1}-x_{1}^{i}\right) \sin \alpha^{e}}{l_{d}^{e}} & \frac{\left(x_{1}-x_{1}^{i}\right) \cos \alpha^{e}}{l_{d}^{e}}
\end{array}\right],
$$

where $\left(x_{1}, x_{2}\right)$ are the coordinates of any point inside the element, $\left(x_{1}^{i}, x_{2}^{i}\right)$ are the coordinates of the first tip of the discontinuity, $l_{d}^{e}$ and $\alpha^{e}$ are, respectively, the length and angle of the discontinuity. $\mathbf{M}_{w}^{e k}$ is obtained by calculating Eq. (6) at each regular node of the finite element and stacking the result into rows.

Following standard finite element procedures, the previous equations can be used to discretise Eq. (4) into the following system:

$$
\left[\begin{array}{cc}
\mathbf{K}_{\mathrm{a \hat {a }}}^{e} & -\mathbf{K}_{\mathrm{aw}}^{e} \\
-\mathbf{K}_{\mathrm{aw}}^{e} & \mathbf{K}_{\mathrm{ww}}^{e}+\mathbf{K}_{d}^{e}+\mathbf{K}_{p}^{e}
\end{array}\right]\left\{\begin{array}{c}
\mathrm{d} \mathbf{a}^{e} \\
\mathrm{~d} \mathbf{w}^{e}
\end{array}\right\}=\left\{\begin{array}{c}
\mathrm{d} \hat{\mathbf{f}}^{e} \\
\mathrm{~d} \mathbf{f}_{w}{ }^{e}-\left(\mathbf{H}_{\Gamma_{d}} \mathbf{M}_{w}{ }^{e k}\right)^{T} \mathrm{~d} \hat{\mathbf{f}}^{e}
\end{array}\right\},
$$

where $\mathbf{K}_{\text {âa }}^{e}$ is the stiffness of a regular finite element, $\mathbf{K}_{d}^{e}$ is the stiffness of the discontinuity, $\mathbf{K}_{\mathrm{aw}}^{e}=\mathbf{K}_{\hat{\mathrm{a} a \hat{a}}}^{e} \mathbf{H}_{\Gamma_{d}}^{e} \mathbf{M}_{w}^{e k}, \mathbf{K}_{\mathrm{wa}}^{e}=\mathbf{K}_{\mathrm{aw}}^{e T}$, and $\mathbf{K}_{\mathrm{ww}}^{e}=\left(\mathbf{H}_{\Gamma_{d}}^{e} \mathbf{M}_{w}^{e k}\right)^{T} \mathbf{K}_{\hat{\mathrm{a}} \hat{\mathbf{a}}}^{e} \mathbf{H}_{\Gamma_{d}}^{e} \mathbf{M}_{w}^{e k}$. Finally, $\mathbf{K}_{p}^{e}$ assures appropriate shear jump transmission along the discontinuity (more details in $[11,24]$ ). 


\subsection{Crack propagation and solution procedure}

The Rankine criterion is used to identify the onset of cracking, with new cracks being introduced through the centre of the cracked element. In the case of crack propagation, the new crack segment is inserted from the crack tip after evaluating the stress field using a procedure that smooths the stress within an average support length of two or three times the typical element size (see [3]). The discontinuity always crosses the entire finite element, with the new degrees of freedom being treated as global unknowns.

The overall system of equations is solved using the Non-Iterative Energy Based Method (NIEM) [25]. According to this method, an incremental analysis is performed until reaching critical bifurcation points. In this situation, a transition to a total approach is performed such that damage is enforced according to information retrieved during the analysis. An energy criterion follows the path leading to the highest dissipation of energy. A comprehensive discussion about this algorithm is found in $[25,26]$.

\section{EXPERIMENTAL TESTS}

The structural scheme adopted for the experimental tests is shown in Figure 1. A total of four beams were grouped into two sets - designated by $1 \mathrm{~T}$ and $3 \mathrm{~T}$ - according to the longitudinal tensile reinforcement ratios, respectively $1.12 \%$ and $2.96 \%$. These ratios were selected to mobilise two limit failure responses: one more ductile and corresponding to an underreinforced failure mode, and the other more brittle and corresponding to an over-reinforced failure mode (see Figure 2).

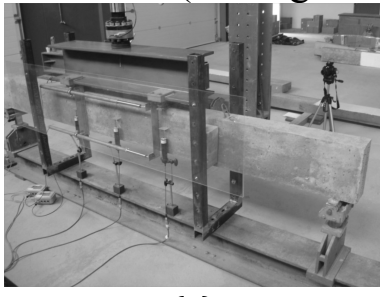

(a)

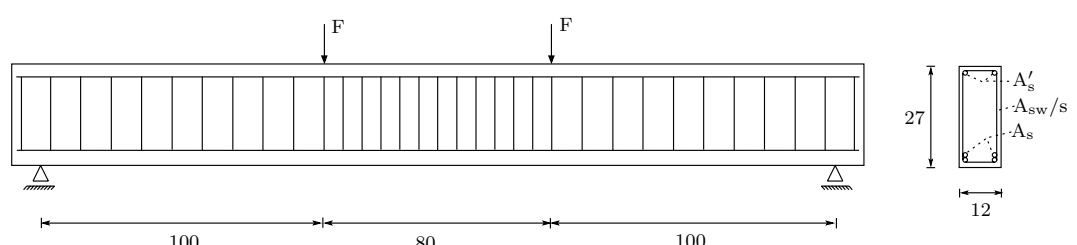

(b)

Figure 1: (a) Loading and measurement apparatus; (b) structural scheme (dimensions in 'mm').

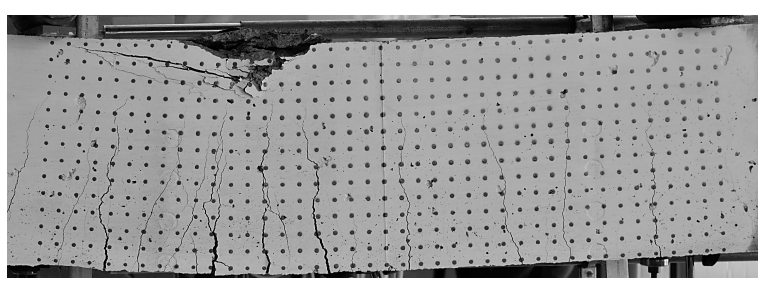

(a)

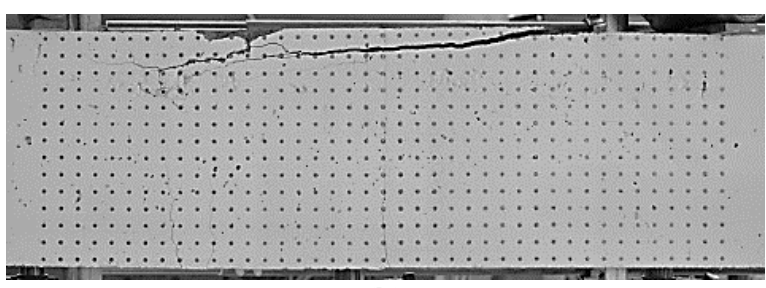

(b)

Figure 2: Failure mode of specimens: (a) 1T; and (b) 3T.

The steel reinforcement adopted for each beam is shown in the following table.

\begin{tabular}{|c|c|c|c|c|c|}
\hline \multirow[t]{2}{*}{ Specimen } & \multirow{2}{*}{$\begin{array}{c}\mathrm{As}_{\mathrm{s}} \\
\left(\mathrm{cm}^{2}\right)\end{array}$} & \multirow{2}{*}{$\begin{array}{c}\text { Effective } \\
\text { depth } \\
(\mathrm{cm})\end{array}$} & \multirow{2}{*}{$\begin{array}{c}\mathrm{A}^{\prime}{ }_{\mathrm{s}} \\
\left(\mathrm{cm}^{2}\right)\end{array}$} & \multicolumn{2}{|c|}{$\begin{array}{c}\mathrm{A}_{\mathrm{sw}} / \mathrm{s} \\
\left(\mathrm{cm}^{2} / \mathrm{m}\right)\end{array}$} \\
\hline & & & & near supports & middle span \\
\hline \multirow{2}{*}{$1 \mathrm{~T}$} & \multirow{2}{*}{3.14} & \multirow{2}{*}{23.4} & \multirow{2}{*}{0.57} & \multicolumn{2}{|c|}{0.47} \\
\hline & & & & 0.47 & 1.34 \\
\hline \multirow{2}{*}{$3 \mathrm{~T}$} & \multirow{2}{*}{8.04} & \multirow{2}{*}{22.6} & \multirow{2}{*}{0.57} & \multicolumn{2}{|c|}{0.47} \\
\hline & & & & 0.47 & 1.34 \\
\hline
\end{tabular}

Table 1: Steel reinforcement for each tested beam. 
All beams were produced using LWAC with an average density of $1870 \mathrm{~kg} / \mathrm{m}^{3}$, compressive and tensile strengths of $57 \mathrm{MPa}$ and $4 \mathrm{MPa}$, respectively, and a Young's modulus of $25.5 \mathrm{GPa}[27,28]$. The longitudinal and transverse reinforcement consisted of hot rolled and ribbed S500NR-SD class bars, with an average yield stress of 545 and an average tensile strength of $645 \mathrm{MPa}$ [29]. Each beam was instrumented using traditional measurement devices to monitor load and the vertical displacements at the three points shown in Figure 1(a). The crack openings were measured for one beam during the test [30-32].

Figure 3 shows the load vs. displacement curves for all tested specimens and a representation of all stages monitored. In this chart, the displacements were measured at the mid-span. As a general remark, four phases can be identified in the overall structural response of the beams. The first or initial phase corresponds to the uncracked stage and is characterised by the highest value in terms of flexural stiffness. This phase finishes at the onset of cracking and the second phase then progresses until the steel reinforcement starts to yield. After this, the third phase is characterised by a significant reduction of flexural stiffness, which ends at the point of maximum load. The fourth and last phase depends on the ductility of the specimen and is the post-peak softening response. This last stage can be quite insignificant in the case of the beams with the highest longitudinal reinforcement ratio.

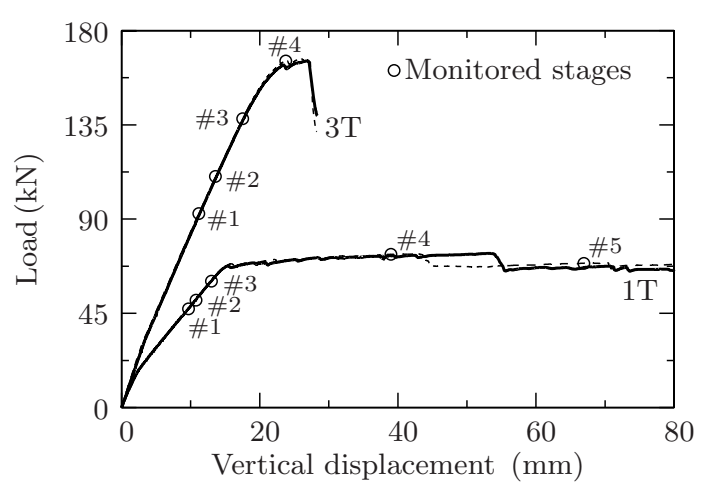

Figure 3: Load vs. mid-span displacement curves and monitored stages.

\section{NUMERICAL MODELLING AND VALIDATION}

The beams described in the previous section were simulated under plane stress conditions. The concrete was modelled using bilinear elements, whereas linear truss elements were used for steel reinforcements (see Figure 4). In what regards constitutive models, the reinforcements were connected to the concrete elements using interface elements equipped with the Model Code 2010 bond model [33]. The concrete elements were assumed to be linear elastic and perfectly plastic under compression, whereas the discrete crack approach model described in Section 2 was used for the elements where the tensile strength of the material was reached. All embedded cracks followed a mode-I traction separation law with exponential softening and fracture energy equal to $0.10 \mathrm{~N} / \mathrm{mm}$.

The numerical model is explored and validated in this section in its ability to simulate crack opening and patterns, and the overall behaviour, namely displacements and curvatures.

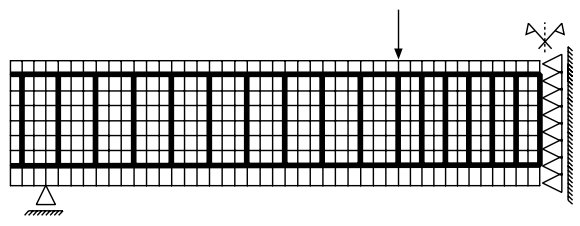

Figure 4: Finite element mesh. 


\subsection{Displacements and curvatures}

The load vs. displacement curves obtained with all numerical models are shown in Figure 5. Comparison between numerical and experimental data shows that the numerical model can predict the overall behaviour for the first three phases. Regarding the post-peak branch, however, there is an inherent inability to predict any of the softening found in the beams with the highest reinforcement ratio. This limitation can be explained by the plastic constitutive model used for concrete crushing, which cannot simulate the real behaviour beyond that. As expected, the transverse steel reinforcement ratio has nearly no impact on both experimental and numerical results (see Table 1 and Figure 5) since no shear cracks developed.

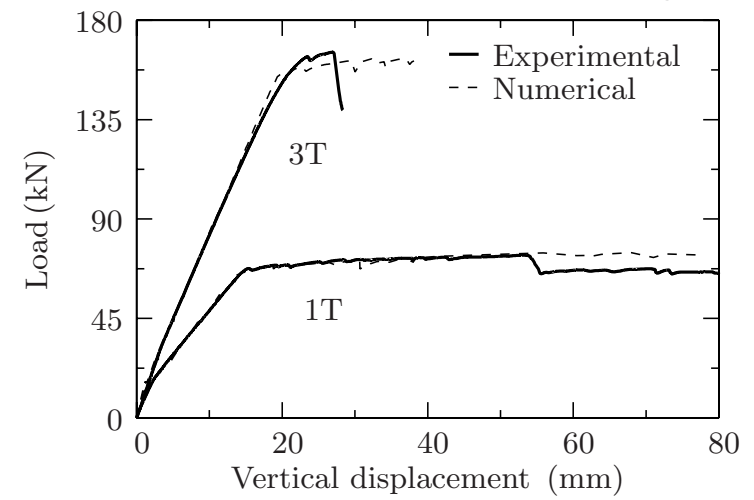

(a)

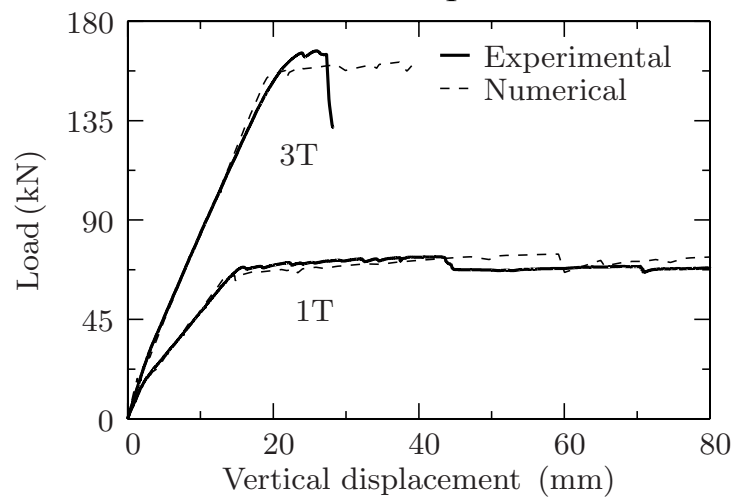

(b)

Figure 5: Load vs. vertical mid-span displacement for the: (a) lowest; and (b) highest transverse steel reinforcement ratios.

Table 2 summarises the main features and measures extracted for the models with highest transverse reinforcement ratio. Comparison between numerical and experimental results, shows the good agreement not only in overall displacements, but also in what regards cracking and yielding loads, maximum load, as well as in the curvature at mid-span (see also Figure 6).

\begin{tabular}{|c|c|c|c|c|c|}
\hline & & \multicolumn{2}{|c|}{ Specimen 1T } & \multicolumn{2}{|c|}{ Specimen 3T } \\
\hline & & Exp. & Num. & Exp. & Num. \\
\hline \multicolumn{2}{|c|}{ Cracking load (kN) } & 12.0 & 13.7 & 15.7 & 15.3 \\
\hline \multicolumn{2}{|c|}{ Yielding load (kN) } & 68.0 & 66.1 & 157.9 & 155.3 \\
\hline \multicolumn{2}{|c|}{ Max. load $F_{\max }(\mathrm{kN})$} & 73.4 & 75.3 & 166.6 & 160.6 \\
\hline \multirow{3}{*}{$\begin{array}{l}\text { Mid-span } \\
\text { vertical } \\
\text { disp. }(\mathrm{mm})\end{array}$} & $0.6 \mathrm{~F}_{\max }$ & 8.4 & 8.0 & 12.2 & 12.2 \\
\hline & $0.7 \mathrm{~F}_{\max }$ & 10.2 & 10.6 & 14.0 & 14.2 \\
\hline & $0.8 \mathrm{~F}_{\max }$ & 11.8 & 11.7 & 16.9 & 16.3 \\
\hline \multirow{3}{*}{$\begin{array}{l}\text { Curvature } \\
\left(\mathrm{x} 10^{-3} \mathrm{~m}^{-1}\right)\end{array}$} & $0.6 \mathrm{~F}_{\max }$ & 9.4 & 8.4 & 12.4 & 14.4 \\
\hline & $0.7 \mathrm{~F}_{\max }$ & 11.2 & 13.4 & 14.3 & 16.2 \\
\hline & $0.8 \mathrm{~F}_{\max }$ & 12.8 & 14.6 & 17.2 & 19.0 \\
\hline
\end{tabular}

Table 2: Summary of the most relevant measures retrieved from numerical and experimental data.

\subsection{Crack propagation}

This section focuses in particular the surface crack pattern and crack openings. In terms of overall pattern, Figure 7 shows a comparison between numerical and experimental data for the lowest longitudinal reinforcement ratio. This specimen was selected for illustration purposes since it is the one showing the most visible cracks (in terms of its number and extension). To support this analysis, the region of interest is represented inside a dashed box in 
Figure 7 (a), which can be directly compared with the monitored area shown in Figure 7 (b). Although real crack patterns can be quite random, the main features are well captured by the numerical model. For example, the model predicts well both spacing and number of active cracks. This is certainly related with the interaction between longitudinal reinforcement and cracks, as well as the relative slip between reinforcements and concrete. It should also be highlighted that the numerical model also predicts the horizontal cracks associated with concrete crushing (see Figure 7).

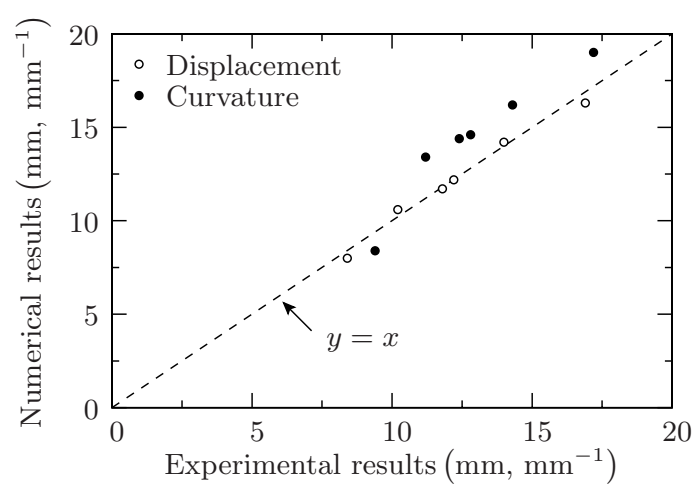

Figure 6: Comparison between displacements and curvatures.

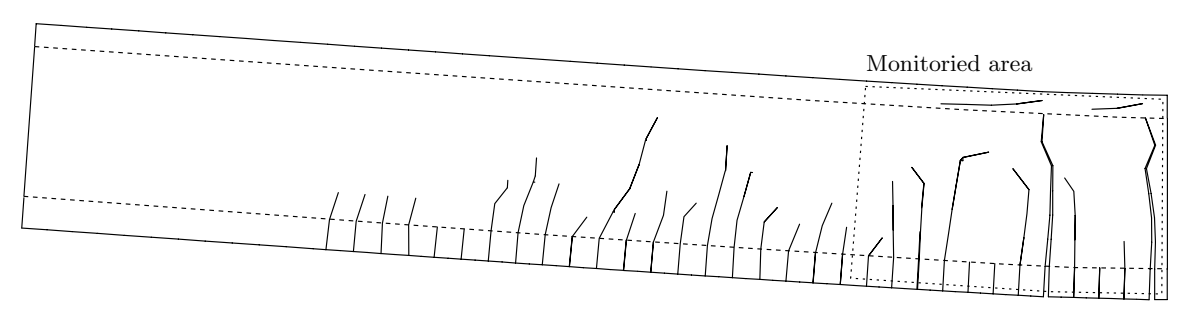

(a)

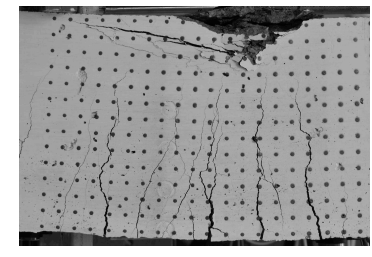

(b)

Figure 7: (a) Failure mode and crack pattern for beam 1T: (a) numerical; and (b) experimental results.

Figure 8 shows the sum of the opening of all the cracks located inside the monitored area at the level of the longitudinal reinforcement, for both types of beams and for the different stages identified in Figure 3. As a general remark, it can be mentioned that the crack openings are in good agreement with the experimental results, regardless of the amount of steel reinforcement and the failure mechanisms being quite different between models. As expected, the crack openings for the beam with higher longitudinal reinforcement ratio are significantly smaller (see also Figure 2).

\section{EXTRAPOLATIONS BASED ON THE NUMERICAL MODEL}

This section presents a study on the role of the longitudinal reinforcement ratio for LWAC beams. Models $1 \mathrm{~T}$ and $3 \mathrm{~T}$ are now re-analysed with models $0.5 \mathrm{~T}, 2 \mathrm{~T}$ and $5 \mathrm{~T}$, respectively having a reinforcement ratios of $0.58 \%, 2.06 \%$ and $4.63 \%$. Models $0.5 \mathrm{~T}$ and $5 \mathrm{~T}$ are close to the minimum and maximum tensile reinforcement ratios allowed by the Eurocode 2 [34]. The objective is to assess the design code in what regards crack openings for LWAC under flexural loads. Figure 9(a) shows the load vs. vertical displacements for all numerical models and the impact different longitudinal reinforcement ratios have on the overall response. 


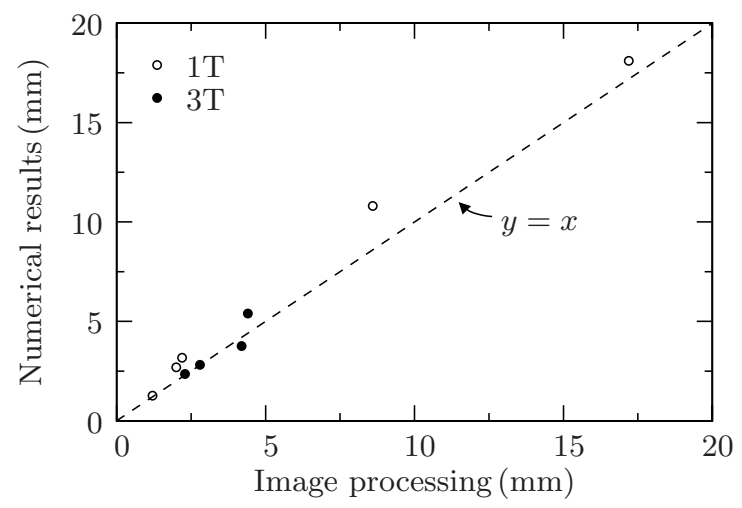

Figure 8: Comparison between experimental and numerical crack openings for both beams with the highest transverse reinforcement ratio.

The characteristic crack width can be defined as the crack opening corresponding to the $95 \%$ percentile value of the distribution. Since the numerical model has a discrete representation of cracks, a statistical model can be directly applied to quantify the characteristic opening at the level of the tensile reinforcements [35]. Figure 9(b) shows the characteristic opening obtained with the numerical models and the estimate from Eurocode 2 [34], the latter below the expected values for all the range of tested reinforcements. Although further studies are still needed, this could mean that the Eurocode 2 [3434] is not conservative for predicting characteristic crack openings in LWAC beams under flexural loads.

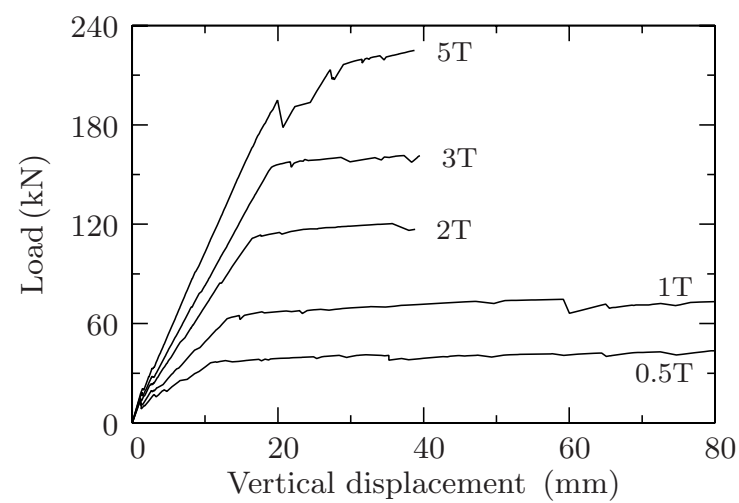

(a)

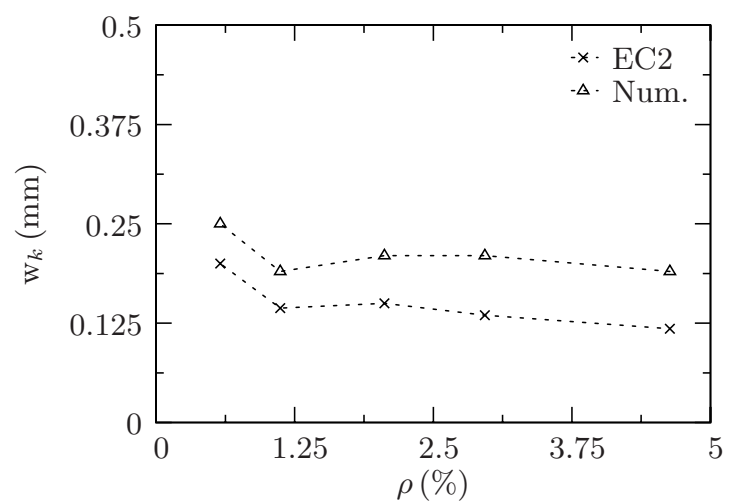

(b)

Figure 9: (a) Load vs. vertical mid-span displacement for all models; (b) Comparison between characteristic crack widths for $0.6 \mathrm{~F}_{\max }$.

\section{CONCLUSIONS}

This study validated a numerical model based on the embedment of strong discontinuities for the simulation of LWAC beams. The model relies on the assumption that the opening of the cracks occurs as if it were a rigid body motion, which simplifies the derived equations and implementation procedure. The model was shown to compare well with experimental data of LWAC beams. The numerical results are in good agreement, not only concerning displacements and curvatures, but also regarding the cracking and yielding loads, and maximum load. In addition, the crack pattern obtained from the simulations captures the main features observed in the laboratory, including the number and spacing of active cracks, as well as the overall opening of the cracks. This highlights the capability of the model to properly simulate the fracture and its interaction with the steel reinforcement, and the slip between reinforce- 
ments and concrete. It was also shown that for the tested range of reinforcements, Eurocode 2 might underestimate the characteristic crack openings for LWAC beams under flexure. This conclusion, however, will need further studies.

\section{ACKNOWLEDGEMENTS}

The first author would like to acknowledge the support from the Australian Research Council through its Discovery Early Career Researcher Award (DE150101703) and from the Faculty of Engineering \& Information Technologies, The University of Sydney, under the Faculty Research Cluster Program. Acknowledgment is also extended to FCT (Portuguese Foundation for Science and Technology), through ISISE, under project UID/ECI/04029/2013.

\section{REFERENCES}

[1] Belytschko, T. and T. Black, Elastic crack growth in finite elements with minimal remeshing. International Journal for Numerical Methods in Engineering, 45(5), 601$620,1999$.

[2] Moës, N., J. Dolbow, and T. Belytschko, A finite element method for crack growth without remeshing. International Journal for Numerical Methods in Engineering, 46(1), 131-150, 1999.

[3] Wells, G.N. and L.J. Sluys, A new method for modelling cohesive cracks using finite elements. International Journal for Numerical Methods in Engineering, 50(12), 26672682, 2001.

[4] Areias, P.M.A. and T. Belytschko, Analysis of three-dimensional crack initiation and propagation using the extended finite element method. International Journal for Numerical Methods in Engineering, 63(5), 760-788, 2005.

[5] Dvorkin, E.N., A.M. Cuitiño, and G. Gioia, Finite elements with displacement interpolated embedded localization lines insensitive to mesh size and distortions. International Journal for Numerical Methods in Engineering, 30(3), 541-564, 1990.

[6] Oliver, J., Modelling strong discontinuities in solid mechanics via strain softening constitutive equations. Part 2: Numerical simulation. International Journal for Numerical Methods in Engineering, 39(21), 3601-3623, 1996.

[7] Jirásek, M. and T. Zimmermann, Embedded crack model: Part I. basic formulation. International Journal for Numerical Methods in Engineering, 50(6), 1269-1290, 2001.

[8] Wells, G.N. and L.J. Sluys, Three-dimensional embedded discontinuity model for brittle fracture. International Journal of Solids and Structures, 38(5), 897-913, 2001.

[9] Linder, C. and F. Armero, Finite elements with embedded strong discontinuities for the modeling of failure in solids. International Journal for Numerical Methods in Engineering, 72(12), 1391-1433, 2007.

[10] Alfaiate, J., G.N. Wells, and L.J. Sluys, On the use of embedded discontinuity elements with crack path continuity for mode-I and mixed-mode fracture. Engineering Fracture Mechanics, 69(6), 661-686, 2002. 
[11]Dias-da-Costa, D., et al., An embedded formulation with conforming finite elements to capture strong discontinuities. International Journal For Numerical Methods In Engineering, 93(2), 224-244, 2013.

[12] Ingraffea, A.R., et al., Fracture mechanics of bond in reinforced concrete. Journal of Structural Engineering, 110(4), 871-890, 1984.

[13]Bocca, P., A. Carpinteri, and S. Valente, Mixed mode fracture of concrete. International Journal of Solids and Structures, 27(9), 1139-1153, 1991.

[14] Areias, P.M.A., et al., Arbitrary bi-dimensional finite strain cohesive crack propagation. Computational Mechanics, 45(1), 61-75, 2009.

[15]Chandra, S. and L. Berntsson, Lightweight aggregate concrete. 2002: William Andrew.

[16]EuroLightCon, BE96-3942/R2: LWAC material properties. State-of-the-Art. 1998: European Union-Brite EuRam III.

[17]EuroLightCon, BE96-3942/R22: The economic potential of lightweight aggregate concrete in c.i.p. concrete bridges. 2000: European Union-Brite EuRam III.

[18]Costa, H., Lightweight aggregate structural concrete: precast and strengthening of existing structures., in Civil Engineering Department 2012, University of Coimbra: Coimbra.

[19]Sajedi, F. and P. Shafigh, High-Strength Lightweight Concrete Using Leca, Silica Fume, and Limestone. Arabian Journal for Science and Engineering, 37(7), 1885-1893, 2012.

[20]Cui, H.Z., et al., Effect of lightweight aggregates on the mechanical properties and brittleness of lightweight aggregate concrete. Construction and Building Materials, 35, 149-158, 2012.

[21]Bogas, J.A., A. Gomes, and M.F.C. Pereira, Self-compacting lightweight concrete produced with expanded clay aggregate. Construction and Building Materials, 35, 1013-1022, 2012.

[22]Felicetti, R., P.G. Gambarova, and P. Bamonte, Thermal and mechanical properties of light-weight concrete exposed to high temperature. Fire and Materials, 37(3), 200-216, 2013.

[23] Malvern, L.E., Introduction to the mechanics of a continuous medium. 1969, Englewood Cliffs, New Jersey: Prentice-Hall International. 713.

[24]Dias-da-Costa, D., et al., A comparative study on the modelling of discontinuous fracture by means of enriched nodal and element techniques and interface elements. International Journal of Fracture, 161(1), 97-119, 2010.

[25] Graça-e-Costa, R., et al., A non-iterative approach for the modelling of quasi-brittle materials. International Journal of Fracture, 178(1-2), 281-298, 2012.

[26] Graça-e-Costa, R., et al., Generalisation of non-iterative methods for the modelling of structures under non-proportional loading. International Journal of Fracture, 182(1), 21-38, 2013.

[27] Carmo, R.N.F., et al., Influence of both concrete strength and transverse confinement on bending behavior of reinforced LWAC beams. Engineering Structures, 48, 329-341, 2013. 
[28]Carmo, R.N.F. and D. Dias-da-Costa, Tensile and flexural behaviour of LWAC members under short-term service loads. Engineering Structures, 92, 142-155, 2015.

[29]EN 10002-1. 2001. Tensile testing of metallic materials - Part 1: Method of Test at Ambient Temperature, 2001, European Committee for Standardisation: Brussels, Belgium.

[30]Dias-da-Costa, D., J. Valença, and R.N.F. Carmo, Curvature assessment of reinforced concrete beams using photogrammetric techniques. Materials and Structures, 1-16, 2013.

[31] Valença, J., et al., Automatic crack monitoring using photogrammetry and image processing. Measurement, 46(1), 433-441, 2013.

[32] Valença, J., D. Dias-da-Costa, and E.N.B.S. Júlio, Characterisation of concrete cracking during laboratorial tests using image processing. Construction and Building Materials, 28(1), 607-615, 2012.

[33] fib, Model Code for Concrete Structures 2010. 2013: Wiley-VCH Verlag GmbH \& Co. KGaA.

[34]CEN, EN 1992-1-1: Eurocode 2: Design of concrete structures - Part 1-1: General rules and rules for buildings, 2004, European Committee for Standardization (CEN).

[35]Borosnyól, A. and G.L. Balázs, Models for flexural cracking in concrete: The state of the art. Structural Concrete, 6(2), 53-62, 2005. 